\title{
BENDITO LOUVADO SEJA \\ NOTAS ETNOGRÁFICAS SOBRE OS CANTORIOS RELIGIOSOS \\ DAS FOLIAS DE URUCUIA-MG
}

Luzimar Paulo Pereira (UFRJ)

As folias são rituais de trocas sociais e simbólicas. Uma de suas marcas mais importantes é a execução de "cantorios". Mais do que o proferimento de versos sobre a base melódica e harmônica de uma música, eles colocam em operação o movimento coordenado dos corpos em relação a um sistema de objetos. Neste artigo, analiso o papel dessas perfomances rituais durante os cerimoniais executados para demarcar o início oficial dos acontecimentos festivos.

RITUAL, PERFORMANCE, FOLIAS, CANTORIOS. 
Como em outros lugares do país, o vocábulo folia também evoca no município de Urucuia, Minas Gerais, a realização de longas jornadas festivas, quando grupos de cantadores e instrumentistas (os foliões) visitam, durante um período de tempo determinado pelo calendário religioso, as casas, as fazendas, os cemitérios e as igrejas de um territó-

1 Mauss ainda procura desfazer a distinção entre ação e linguagem ao afirmar que o puro rito oral é um ato, enquanto ritos manuais podem ser simbólicos.

2 Meu trabalho etnográfico foi realizado entre 2005 e 2008. Gostaria de prestar meus agradecimentos a todos os promotores e participantes dos festejos urucuianos que me receberam com paciência e generosidade ao longo de meus trabalhos de campo. Também quero agradecer aos professores José Reginaldo Santos Gonçalves, Maria Laura Viveiros de Castro, Marco Antonio Gonçalves, Marcia Contins e Renata de Castro Menezes os comentários estimulantes durante a defesa de minha tese de doutoramento. Minha pesquisa de campo contou com o apoio financeiro do Conselho Nacional de Desenvolvimento Científico e Tecnológico (CNPq), e este artigo foi escrito com o apoio da Coordenação de Aperfeiçoamento de Pessoal de Nível Superior (CAPES), via Programa de Apoio a Projetos Institucionais com a Participação de Recém-Doutores (PRODOC). rio previamente estabelecido. As jornadas são conhecidas como os "giros das folias". Nelas, os grupos se deslocam para coletar, em nome de cada um dos santos homenageados pelos festejos e de seus principais patrocinadores (os imperadores), as oferendas necessárias e obrigatórias ao custeio de uma reza a ser realizada no dia dedicado a cada divindade. Em troca do que é recolhido - dinheiro, velas, fogos de artifício, sacas de arroz, feijão, animais de criação, etc. -, eles distribuem bênçãos aos doadores, além de auxiliá-los no cumprimento de suas promessas e contribuir para que almoços, jantares e bailes sejam oferecidos em suas passagens. Mais do que apenas grupo precatório, as folias são verdadeiros fatos sociais totais (BRANDÃO, 1981; PEREIRA, 2004; 2009; BITTER, 2010). Nelas, homens e divindades, personagens cerimoniais e pessoas comuns, vivos e mortos, famílias e indivíduos, todos, enfim, se veem presos a uma extensa rede em que bens e serviços morais, religiosos, econômicos, estéticos, etc. são trocados, doados, recebidos e retribuídos (MAUSS, 2003).

O "cantorio" é uma das principais atividades desempenhadas pelos foliões ao longo de suas viagens cerimoniais. Central no mundo das folias urucuianas, ele também é observado em diversos outros festejos populares do Brasil (BRANDÃo, 1981; QUEIROZ, 1973; entre outros). No conhecido Dicionário do Folclore Brasileiro, de Câmara Cascudo, o "cantorio" é definido como o "ato da cantar, a disputa poética cantada, o desafio entre os cantadores do Nordeste brasileiro" (CASCUDO, 1998, p. 238). Nas folias de Urucuia, entretanto, ele não parece resumir-se ao simples proferimento de versos rimados e entoados sobre a base ritmada, melódica e harmônica de uma música. Nesses contextos, o "cantorio" corresponde a um conceito bastante mais estendido do que a simples ideia de poesia cantada. Ainda que os versos entoados tenham alguma proeminência, eles precisam colocar em operação o movimento coordenado dos corpos em relação a um verdadeiro sistema de objetos (BAUDRILLARD, 2004). Não há música separada das falas nem cantos separados de artefatos e do movimento corporal de seus participantes. Embora possa ser considerado uma espécie de rito oral, o "cantorio" também mantém laços estreitos de contiguidade com os rituais manuais (MAUSS, 1999) ${ }^{1}$. 
A eficácia do "cantorio" é garantida pela dissolução temporária das fronteiras entre material e imaterial, o corpo e o espírito, a linguagem falada e a poética cantada. Os gestos e os proferimentos de palavras se misturam para produzir um enquadramento semântico em que operações metafóricas e metonímicas, de contágio e de semelhança, são postas em operação. Num estudo sobre rituais de transferência mágica realizados pelos trobriandeses, Stanley Tambiah entende que certos objetos e substâncias têm papel de mediação. Seus usos cerimoniais podem ser compreendidos através dos princípios da similaridade e do contágio. $O$ autor assinala que uma análise mais profunda dos rituais revelaria que eles "ativamente exploram as propriedades da linguagem, as qualidades sensoriais dos objetos e as propriedades instrumentais da ação, simultaneamente e de diversas maneiras" (TAMBIAH, 1985, p. 37).

Neste artigo², analiso o papel ritual do "cantorio" a partir da descrição de uma das etapas mais importantes das festas de folia urucuianas: a retirada. Realizada na moradia de seus principais organizadores (os imperadores), a retirada pode ser descrita como um conjunto de pequenos cerimoniais religiosos que ocorrem durante parte de um único dia e cujo objetivo central é demarcar o início oficial dos acontecimentos. Como as "entradas" dos rituais de passagem descritos e analisados por diversos autores (MAUSS, 1999; VAN GENNEP, 1978; TURNER, 1974; entre outros), sua função é conferir caráter religioso aos personagens, aos lugares e aos instrumentos acionados durante a realização dos festejos. Antes de efetivamente a festa começar, todos os seus elementos estão excessivamente imbuídos de valores cotidianos. "É preciso", em poucas palavras, que eles "mudem de estado" (HUBERT \& MAUSS, 1999, p. 156). Durante a retirada uma morte simbólica prepara o renascimento para o novo tempo que começará a seguir.

\section{OS CANTOS DA RETIRADA DE UMA FOLIA DE SANTA LUZIA ${ }^{3}$}

Na tarde do dia 12 de dezembro de 2007, o capitão Ivan Gombé pedia aos seus foliões que se posicionassem em frente ao santuário de Santa Luzia para que tivesse início a retirada da folia realizada em nome de dona Jura e seu Rubens ${ }^{4}$. O líder dos cantadores fazia algumas recomendações a seus companheiros, reiterando, através de um pequeno discurso, as "obrigações" de todos os envolvidos com a jornada que iria começar. A peregri-
3 As folias urucuianas são dedicadas aos mais variados santos do panteão católico. Há as folias dos Santos Reis, de São Sebastião, São José, Bom Jesus da Lapa, Nossa Senhora Aparecida e Santa Luzia, citando apenas as mais importantes. Todas elas se realizam em épocas precisas, de acordo com o calendário religioso que estabelece dias específicos para cada entidade: 6.1, Santos Reis; 20.1, São Sebastião; 19.3, São José; 10.8, Bom Jesus da Lapa; 12.10, Nossa Senhora Aparecida; e 13.12, Santa Luzia. As datas marcadas pelo calendário religioso para a realização de cada um dos festejos constituem, no entanto, apenas um ponto de referência para sua execução. Uma folia pode durar de um a 12 dias, antecedendo sua data oficial, a depender do santo ao qual ela é dedicada ou do conteúdo dos votos dos seus principais organizadores e patrocinadores.

4 Há cerca de 16 anos, ela estava grávida de seu quinto filho. A gestação, no entanto, foi difícil, e a criança, em função das complicações vividas durante esse período, nasceu morta. Para piorar, o malogrado parto acabou trazendoIhe sequelas. Ela adoeceu, e seu olho direito não abria mais. Além disso, perdeu o controle dos movimentos de braços e pernas. Sentindo-se "fraca", não con- 
seguia sequer se levantar da cama para realizar suas atividades cotidianas em casa. Dona Jura procurou, então, o posto de saúde de sua cidade e chegou a ser levada para o hospital geral de Arinos, a cerca de $50 \mathrm{~km}$ de Urucuia. $\mathrm{Ne}$ nhum médico, entretanto, conseguia resolver seus problemas. Num ato de desespero e contrição, rogou à santa por um benefício: "eu pedi para ela que se curasse meu olho e se eu ficasse boazinha, eu havia de fazer uma reza para ela todo ano no dia 13 de dezembro, até morrer. E assim foi." Ela se curou cerca de duas semanas depois de realizada a promessa. Ao acordar, reparou que seu olho abria normalmente. A "graça", como me dizia, ocorreu num final do mês de novembro, poucos dias antes da data das comemorações de Santa Luzia. Ainda sofrendo os efeitos de sua doença, insistiu em começar a saldar, o quanto antes, sua promessa: "Eu estava bastante fraca, mas minhas irmãs ajudaram bastante. Elas quase que fizeram a reza todinha para mim."

5 As orações não são simples textos repetidos mecanicamente. Elas são entendidas como dons deixados por Deus para servir como ferramentas de proteção e de purificação dos homens. "O Pai Nosso e a Ave Maria são as oração que Deus deixou pra gente" (Devoto urucuiano, caderno de campo, 15.1.2008). nação deveria ser feita "com fé" e "contrição", dizia ele, porque se tratava, antes de tudo, de uma "devoção" e de um "compromisso" para com a promessa da "imperadeira" de Santa Luzia. Uma oração se seguiu ao rápido discurso do capitão. Nela, os devotos pediram proteção à santa para que "nada de mal" acontecesse aos viajantes durante a noite que começava. Foliões e imperadores se deram as mãos. Mais além, encontravam-se os demais convidados. Também dando-se as mãos ou acompanhando sozinhos os rituais que ocorriam no centro da sala, eles compunham a parte mais exterior dos dois círculos concêntricos formados pela oração.

A Ave Maria e o Pai Nosso eram preces propiciatórias voltadas para duas personagens centrais do catolicismo popular: o próprio Deus Pai e a Virgem Nossa Senhora (que, em certos momentos, era analogicamente associada a Santa Luzia) $)^{5}$. Segundo Hubert \& Mauss (1999, p. 159), as purificações, lustrações e consagrações que antecedem os rituais religiosos preparam "o profano para o ato sagrado, eliminando-o da vida comum e introduzindo-o, passo a passo, no mundo sagrado dos deuses". Nas festas de folia, os pedidos de purificação e proteção também tinham razões instrumentais. Afinal, no conjunto de crenças e práticas concernentes às jornadas das folias, os riscos são constantes. Os perigos da noite, do frio, do cansaço, da bebida, das muIheres, das brigas entre foliões, das feitiçarias praticadas contra os cantadores ou contra os imperadores, são muito reais, assim como a intervenção de espíritos, que podem atrapalhar a condução dos serviços rituais das companhias durante sua jornada. As orações regulavam a entrada para um mundo em que as distâncias são temporariamente encurtadas, criando espaços liminares potencialmente perigosos (PEREIRA, 2009; DOUGLAS, 1991).

A reza terminou com vivas a Santa Luzia, aos imperadores, aos foliões e a todos os que estavam acompanhando e participando de sua realização. Por um momento, houve alguns segundos de relaxamento, que os cantadores e tocadores aproveitavam para beber água e acertar a afinação de seus instrumentos. Logo, eles formaram um semicírculo diante do santuário. Os imperadores permaneceram de pé. Rubens agora segurava a bandeira de Santa Luzia. Dois grupos se encontravam frente a frente. De um lado, havia o casal de moradores, que, próximo ao santuário, indicava o espaço de onde sairia a folia para sua viagem. De outro, os foliões, posicionados de costas para a saída da 
casa e de frente para os patrocinadores. Os cantadores, em especial, se colocavam segundo um padrão conhecido por seus integrantes. O guia e o contraguia permaneciam à frente do terno, mais próximos do santuário do que os demais tocadores ${ }^{6}$. $\mathrm{O}$ alferes se posicionou no centro do semicírculo, à espera da bandeira que o imperador (homem) Ihe deveria repassar durante o cerimonial (só depois dos comandos específicos do "cantorio" ele sairá desse centro para receber o retrato das mãos dos imperadores) ${ }^{7}$. O círculo limitava o movimento dos participantes. Os que estavam dentro não podiam sair, assim como os que estavam fora não podiam entrar. (Figura 1)

Tão logo teve certeza de que os instrumentos musicais estavam afinados e os foliões corretamente posicionados, o capitão acenou com a cabeça para seus companheiros e executou, com sua viola, a primeira frase melódica de introdução do "cantorio". Acompanhado do seu ajudante, ele começou, então, a entoar os primeiros versos do cerimonial. Suas palavras iniciais foram, na sequência, devidamente repetidas pelo contraguia e seu ajudante. As duas primeiras quadras descreviam, em versos rimados, os gestos iniciais de toda a reza: o "sinal da santa cruz". Lá fora, alguém disparava um rojão para indicar o início dos acontecimentos.

Pelo sinal da santa cruz, / Benza Deus, nosso senhor, / Que nos livrai dos inimigos / Com o sinal que Deus deixou // O nome do Pai, eu faço na testa, / o Filho, eu faço em meu peito. / Do Espírito, eu faço nos ombros / Do esquerdo para o direito.

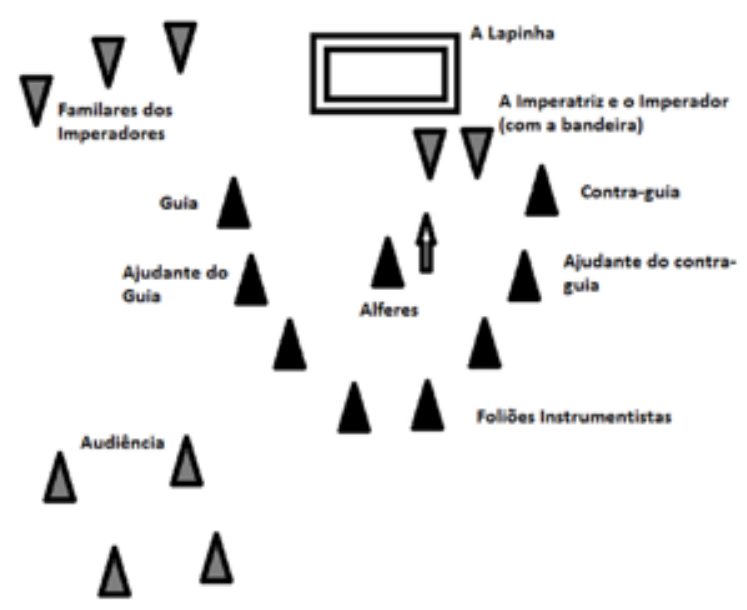

60 capitão se posicionou à esquerda de quem olha segundo o ponto de vista dos demais acompanhantes dos festejos. Responsável por puxar o cantorio, o capitão seria auxiliado por seu ajudante, que se posicionou a sua direita, um pouco mais afastado do altar. O contraguia era o respondedor, geralmente habilitado a repetir, junto com seu ajudante, aquilo que o capitão e seu companheiro cantariam em primeiro lugar. O contraguia se colocou na ponta direita do semicírculo, e seu ajudante, a sua esquerda, estava mais afastado do que ele do altar sagrado. Os demais foliões instrumentistas permaneciam mais distantes, ao fundo.

7 A bandeira, também conhecida como "retrato do santo", é mais do que a representação da unidade do grupo religioso ou simples substituto de uma entidade ausente, o santo (no sentido moderno do termo representação) (GONÇALVES, 2003). Ela é entendida pelos devotos como a presença concreta da pessoa sagrada entre seus fiéis. Nos cantos, nos gestos e nas falas dos

\footnotetext{
Figura 1. Os foliões, os imperadores e a audiência no cantorio da retirada
}

PEREIRA, Luzimar Paulo. Bendito louvado seja: notas etnográficas sobre os cantorios... 
devotos realizados durante os giros, surpreendemos o reconhecimento de seu caráter de entidade. Não se trata aqui de retomarmos a oposição moderna entre matéria e espírito, da qual nos fala Marcel Mauss (2003). Mais do que simples objeto, ela é o santo encarnado; é a materialização de suas virtudes em meio a seus fiéis.

8 A redundância é importante valor ritual e está relacionado ao caráter comunicativo de todos os tipos de rituais. Ver Tambiah (1985).
As quadras sugeriam a proximidade do canto com as preces; apresentando, por meio dos versos que descreviam o gesto manual da oração (o Sinal da cruz), uma espécie de interseção entre a reza realizada anteriormente e o "cantorio" que se iniciava agora. As palavras dos cantadores reforçavam, através da redundância, o sentido de proteção da oração religiosa ${ }^{8}$. O Sinal da cruz precedia os versos de comando do ritual, quando o capitão indicaria aos demais personagens, através das quadras rimadas, tudo o que deveria ser feito para a realização dos cerimoniais.

Ô, Bendito, louvado seja, / Meu divino protetor. / Vamos receber a folia / Desse nobre imperador. // Ô, meu nobre imperador, / Com sua nobre rainha, / Vamos receber sua folia, / Senhora Santa Luzia // Ô, Bendito, louvado seja, / Meu Divino Pai Eterno, / Vamos receber sua folia, / Para cumprir sua promessa. // Vamos receber sua folia, / Para essa santa prometeu. / Que foi visto e reconhecido / Pois os milagre valeu.

Sem citar o nome dos imperadores, os versos anunciauma promessa, resultado de um "milagre" "visto e reconhecido" em nome da santa. Terminada essa sequência introdutória, o capitão deu ensejo ao recebimento da folia no sentido estrito. Chamou a atenção dos imperadores e indicou o que eles deveriam fazer naquela situação.

Ora, meu nobre imperador, / Escuta o que eu vou falar. / A folia de Santa Luzia / Vós irá nos entregar. // Deus o salve, meu imperador / Com o retrato do seu império. / Faz a vênia com esse retrato, / entrega ao meu alferes.

O imperador estava distraído, mas sua esposa, que ouvia atentamente a apresentação, lembrou-lhe aquilo que o capitão Ihe havia determinado: fazer a vênia antes de repassar o retrato santo às mãos do alferes da folia. Também chamada de continência, a vênia é efetuada quando o portador da bandeira faz o Sinal da cruz utilizando o artefato religioso. A cada três vezes que realiza esse movimento, seu portador passa o retrato sobre os foliões que estão na roda, como que os abençoando. A bandeira toca suas cabeças e às vezes seus instrumentos. Ao todo, são três vezes que isso acontece. (Figura 2)

Enquanto o imperador realizava a vênia, o alferes a ele se dirigiu e se ajoelhou para receber de suas mãos o retrato santo de Santa Luzia. A passagem foi seguida por outra continência, dessa vez executada pelo alferes ainda de joelhos. Nos versos seguintes, o capitão indicaria o recebimento da folia, afirmaria ser Santa Luzia a "padroeira" do grupo de foliões e pediria que seus companheiros se ajoelhassem diante do casal de imperadores e do santuário - como o alferes fizera antes.

Deus o salve, nobre alferes / Recebeu essa bandeira. / Senhora Santa Luzia Ela é nossa padroeira. // E nos pé da santa lapinha, / Joelhai, meus folião. / Vamos receber essa promessa / Para cumprir com devoção. 


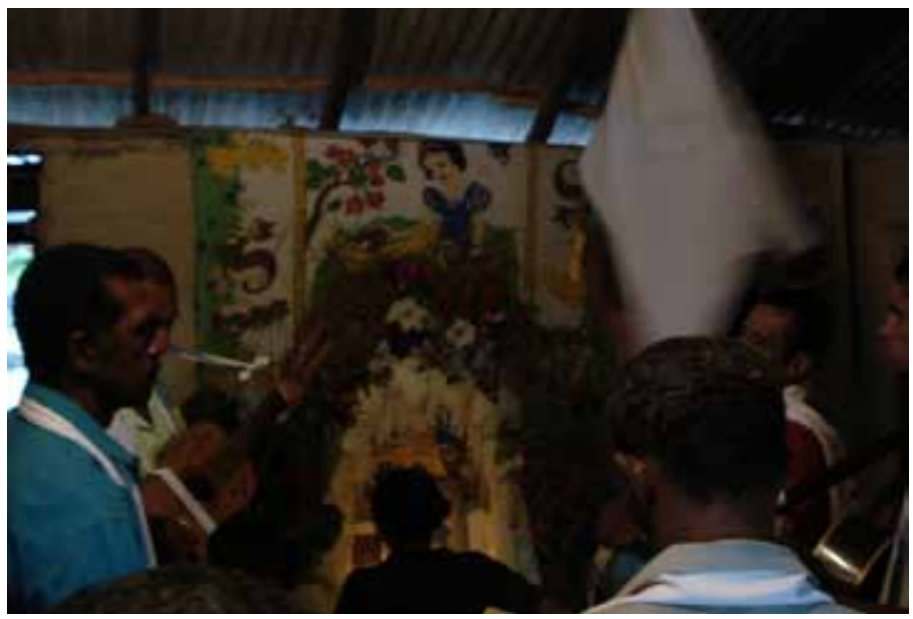

Figura 2. Foliões cantam diante do altar. Note-se, no alto, à direita, o movimento da vênia Foto: Luzimar Paulo Pereira

Os foliões se ajoelharam diante dos imperadores e do santuário. Nos versos seguintes, o capitão reafirmou o recebimento da promessa, acrescentando, dessa vez, que o gesto podia ser materialmente observado a partir da transmissão, efetiva e simbólica, da bandeira, das toalhas e dos instrumentos musicais. O cantador afirmava que cada um desses artefatos era, por si só, parte de um todo maior, representado pela folia da santa homenageada.

Recebendo a santa folia / Com todas as toalhas brancas. / Ô, senhora Santa Luzia / E o Divino Espírito Santo. // Recebemo essa folia, / Viola, caixa e pandeiro. / Que é feita para Santa Luzia / E Jesus Cristo verdadeiro.

Ainda ajoelhados, os foliões cantaram o recebimento, destacando os personagens principais do terno, em conjunto e separadamente: os foliões, o capitão e o alferes. Em seguida, eles anunciaram sua saída para o giro de uma noite pelas casas da região. Na última quadra, o capitão pede que os cantadores se levantem para se realizar a despedida.

Recebemos essa folia / Nos pé da santa lapinha. ${ }^{9}$ / Recebemo com meus folião, / Com o alferes e o guia. // Recebemo a santa folia / Nos pé do império real. / $\mathrm{E}$ aqui hoje recebemos, / Amanhã vem entregar. // Pai eterno desceu do céu / Dirigindo a São Crispim / E ele vem para abençoar / Despedida dessa folia // Ora, meus nobre folião / Aqui nós ajoelhemo. / Como a santa subiu para o céu / Nós também se alevantemo.
9 O santuário é frequentemente denominado lapinha, em referência à lapa em que teria nascido Jesus Cristo (PEREIRA, 2009).

Os foliões se levantaram. Os versos continuaram para convidar os donos da casa e sua família a se despedir do retrato santo. Ao comando do capitão, o imperador e sua esposa, acompanhados, depois, pelos filhos e parentes que a tudo assistiam nas proximidades, se ajoelharam diante da bandeira que o alferes colocou em sua direção. Eles, então, realizaram suas preces, beijando o artefato três vezes e passando-o sobre suas cabeças. A inversão era evidente: se na primeira fase da passagem do retrato, os foliões se 


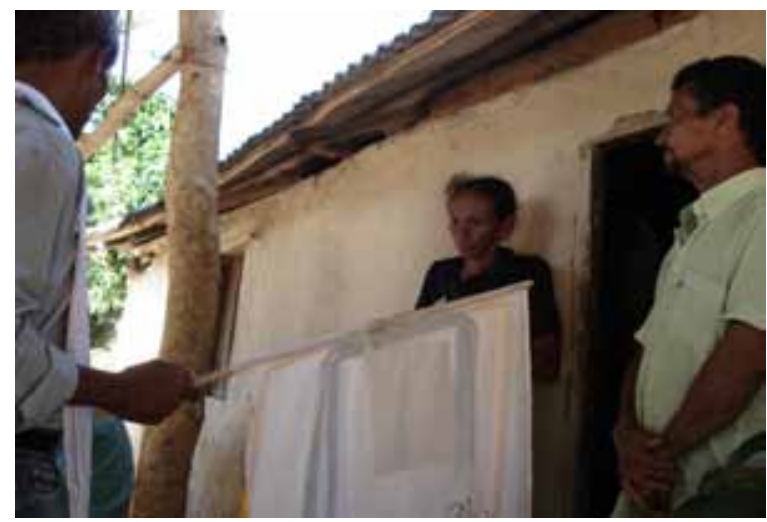

Figura 3. Alferes (à esquerda) se despede dos moradores (à direita) para sair no giro

Foto: Luzimar Paulo Pereira

ajoelharam diante dos imperadores, eram estes agora, junto com amigos e familiares, que se ajoelhavam diante dos foliões.

Ô, meu nobre imperador, / Enconvida sua família / Para beijar o retrato santo, / Despedir da sua folia. // Ora, meu nobre imperador / A santa vai retirar. / Amanhã ao romper do dia / Nós havemo de aqui chegar.

Depois de anunciar o início da viagem e a data do retorno dos foliões, o capitão encerrou o "cantorio" afirmando que a folia seguiria em direção ao "mundo de meu Deus" para "cumprir a promessa" do imperador ao lado da santa "retratada na bandeira". Os versos finais retomavam a ideia inicial de que o "cantorio" é uma espécie de reza, terminando sua execução com uma louvação a Santa Luzia (em certos casos, os cantos terminam com um "amém").

E a santa vai retirando, / Retratada na bandeira. / Vamos cumprir sua promessa / Nesse mundo de meu Deus. // O rosário de Maria / Em Jerusalém foi feito. / Nossa Senhora Santa Luzia / Ô, que santa tão perfeita!

Novos foguetes foram lançados no exterior da casa, enquanto os foliões ainda comandaram três voltas melódicas com seus instrumentos musicais. Quando tudo ficou em

10 o capitão ainda convidou os imperadores a acompanhá-los durante a viagem. Nenhum dos dois podia ir. Dona Jura e Rubens precisavam ficar em casa para continuar a arrumação dos festejos para o dia seguinte, quando se realizaria a entrega de sua folia. "Qualquer problema, vocês manda avisar, que eu vou", ainda anunciava o dono da casa. silêncio, o capitão pediu vivas a todos os presentes, indicando a hierarquia dos personagens do ritual: Nossa Senhora, os imperadores, os foliões e "todos que aqui estão". As pessoas que acompanharam o desfecho do "cantorio" bateram palmas de aprovação. Os cantadores agradeceram pessoalmente aos imperadores e saíram carregando seus instrumentos. $O$ alferes saiu logo em seguida, carregando a bandeira de Santa Luzia em uma de suas mãos. Depois de posicionado no terreiro, ele proferiu as palavras de despedida a seus imperadores: "vocês fica com Deus e Santa Luzia" (a que eles responderam: "E Nossa Senhora Santa Luzia que acompanha vocês") ${ }^{10}$ (Figura 3). O cortejo ainda caminhou um pequeno trecho de terra que levou o grupo de devotos até um sítio vizinho, no qual uma moradora, comadre de dona Jura, estava esperando. A propriedade era a primeira das muitas que 
os foliões visitariam ao longo de toda a noite, até que, na manhã seguinte, voltassem à residência dos imperadores. O giro da "Senhora Santa Luzia", feito em nome da promesseira Jura e de seu esposo Rubens, estava finalmente começando.

\section{OS SENTIDOS DA RETIRADA}

A retirada é um verdadeiro ritual de encontros. Os foliões, os familiares dos imperadores, seus compadres e vizinhos, simples amigos ou até alguns desconhecidos, são todos atraídos - através de convites ou da simples devoção a um santo católico - para a residência em que ocorrem os festejos. Por um momento, o lugar se transforma e adquire feição bem diferente daquela a que estão acostumados seus moradores. Do espaço privado e cotidiano, lugar do trabalho e do descanso do grupo doméstico, ele se torna o local mais público de um território de parentesco, o lugar de festa e devoção comunitária (PEREIRA, 2004; 2009).

A rigor, duas importantes passagens podem ser observadas nessas ocasiões. Por um lado, os festejos borram os limites entre o "dentro" e o "fora" da residência. Seus espaços interiores e suas conexões com os exteriores tornam-se bastante permeáveis. As portas de entrada e saída permanecem sempre abertas para a circulação constante de pessoas. Em muitos casos, para que isso possa acontecer, as transformações do espaço doméstico podem ser bastante radicais. A moradia expande os lugares de mediação com o mundo exterior para além de suas fronteiras convencionais: o barracão da festa, construído para a ocasião, é uma espécie de sala improvisada no terreiro da frente; ao passo que a cozinha dos fundos se transforma, igualmente, numa extensão do domínio feminino no interior da edificação doméstica para seu contíguo exterior. No limite, apenas poucos lugares da residência, como as despensas e os quartos dos donos da casa, permanecem fechados para a maioria dos visitantes. A interdição desses locais, no entanto, só reforça a ênfase na mediação em decorrência das transformações que se verificam na moradia. Ao privilegiar os espaços de transição entre o mundo interior e o exterior, os festejos reiteram certas polaridades, ao mesmo tempo em que instauram situações de perigo, típicas dos estados liminares (DougLAS, 1991).

O dia da retirada também propõe, por outro lado, mediações importantes entre o "alto" e o "baixo", entre "este mundo" e o "outro mundo", coordenando os contatos entre os fiéis e seus santos de devoção. O início oficial das folias é o primeiro momento da apresentação do sagrado, ao introduzir, efetivamente, as entidades religiosas nos festejos ${ }^{11}$. Os santuários são montados, e os santos - encarnados em imagens, quadros e bandeiras -, colocados em seu interior ou proximidade para atestar sua presença no meio dos homens. Também aqui, a casa se transforma em espaço que transcende o local da vida doméstica. Além de ser o lugar público de uma festa comunitária,

11 Suzel Reily observa, em seu estudo sobre os festejos de reis da grande São Paulo, que para orquestrar os contatos entre os mundos divino e terreno, os rituais de uma folia precisam, primeiramente, marcar as distinções entre as duas esferas, através do uso de esquemas performativos que apresentam o espaço ritual apartado do mundo pragmático do dia a dia de seus realizadores (REILY, 2002, p. 128). 
$12 \mathrm{Em}$ trabalho anterior, notei que, durante as folias de reis realizadas num bairro rural do sul do Estado de Minas Gerais, os santos, encarnados na bandeira que carregava seu nome, 'hospedavamse' na moradia de seus devotos durante o ano de vigência de uma festa e durante as visitas que os tocadores faziam às residências de outros devotos (PEREIRA, 2004).

13 "O poder também se manifesta nos intersticios." A ideia está presente em vários trabalhos de Leach (1983; 2000). O mundo "real", pensa o autor, é contínuo. "Mediante o uso de categorias, separamos os espaços físico e social em áreas com diferentes potenciais de poder, criando a ilusão da descontinuidade. Nas interfaces, encontramos uma região que não pertence a nenhuma das categorias, e ao mesmo tempo pertence a ambas. É uma área perigosa, tabu, de poder manifesto" (LEACH, 2000, p. 37). a moradia também se transforma, por algum momento, na morada do santo, onde ele está assentado e hospedado para a realização dos festejos ${ }^{12}$. Quando os convidados chegam à residência, eles precisam cumprimentar seus donos cotidianos, mas devem igualmente saudar seus proprietários divinizados, os santos a quem os acontecimentos são dedicados. As expressões com as quais eles se dirigem aos santuários e às bandeiras depositadas em seu interior ("deixa eu cumprimentar meu santinho", "deixa eu ver nosso santinho", entre outras) confirmam a ideia de que os artefatos são muito mais do que simples objetos, mas a própria materialização das entidades sagradas - o atestado de sua presença entre os homens.

As atividades do dia da retirada são voltadas para o ritual da transmissão da bandeira, através do qual o artefato que encarna os santos homenageados pelas folias é repassado para o grupo de cantadores e tocadores. O cerimonial parece encenar, em si mesmo, a estrutura dos rituais de iniciação e sacrifício descritos por diversos autores (TURNER, 1974; VAN GENNEP, 1978; HUBERT \& MAUSS, 1999; LEACH, 2000; entre outros). Espacialmente, podemos observar que sua realização se dá a partir de uma sucessão de círculos mágicos concêntricos focados no santuário montado no interior da sala de visitas da residência da festa, local onde se assentam as divindades para as quais tudo é realizado. O altar, segundo Leach (2000), é "a fonte do maior poder potencial" da retirada e o foco da interação ritual (TURNER, 1980). Os contatos com ele só podem ser feitos segundo regras específicas de comportamento, pois há limites invisíveis que precisam ser atravessados. Para se aproximar dos santuários e artefatos que estão sob sua influência ou tocá-los, os devotos se ajoelham e executam preces individuais e coletivas em sua direção. Colocado no centro físico e simbólico da residência - sua sala - ele é a morada dos santos, espaço em que se assentam as entidades religiosas na forma da bandeira e dos quadros colocados em seu interior (Figura 4).

No círculo interior, em que se encontra o altar, também observamos o espaço reservado aos personagens da iniciação (os foliões e os imperadores, que se encontram frente a frente). O santuário, por extensão, transforma a sala num espaço intermediário - um betwixt and between, na linguagem de Turner (1980) -, dividido segundo distintos graus de sacralidade ${ }^{13}$. As penumbras do altar demarcam o local em que ocorre a maioria das ações rituais do "cantorio da retirada da bandeira". Trata-se de área intermediária; ela também está neste mundo e no outro simultaneamente, posicionada além do centro físico e simbólico do santuário e, ao mesmo tempo, aquém da periferia do conjunto, em 
que encontramos o leigo, a assistência, onde o sentido de religiosidade é mais fraco (HUBERT \& MAUSS, 1999) (Figura 5).

A região do meio articula as interfaces entre as categorias presentes à realização dos festejos. Os foliões e os imperadores que ali estão posicionados são sujeitos liminares: o imperador ainda não pode ver seu império em atuação (ele precisa de sua folia para pagar sua promessa); e os foliões ainda não receberam efetivamente os artefatos que constituem o giro e a própria unidade de seu terno de folia (a bandeira, as toalhas e os instrumentos). A complementaridade se apresenta ostensivamente. Nenhum dos personagens será completo sem a troca efetiva que ocorre durante o "cantorio da transmissão": para serem mais do que simples devotos, eles precisam intercambiar. A região intermediária é, desse modo, rigidamente marcada ${ }^{14}$. Os que estão localizados no seu interior não podem sair, ao passo que os que estão fora, não podem entrar. $\mathrm{O}$ círculo está fechado. Só o procedimento ritual poderá desfazê-lo depois.

A distribuição rígida dos personagens no interior e no exterior dos círculos concêntricos é paulatinamente quebrada pela sonoridade ritual de uma folia - através dos fogos de artifício e da música entoada - que marcam a descontinuidade do tempo (LEACH, 2000). Um dos elementos centrais desse cerimonial é o cantorio, por meio do qual os foliões conduzem todas as ati-
14 A roda formada diante do santuário possui valor sagrado. Numa ocasião, vi o capitão ralhar com um devoto que - bêbado - insistia em participar, ao lado dos foliões, das rezas que davam início à retirada: "aqui só pode ficar os folião, moço".

15 Sobre o tema da linguagem como forma de comunicação e também de ação, ver Malinowski (1976), Austin, (1990), Tambiah (1985), entre outros. Influenciado por Austin (1990), Chaves (2006) já havia observado a proximidade dos cantorios de folia com os atos de fala. $O$ autor também argumenta que o dizer e o fazer dos cantos não são sempre expressos da mesma forma. vidades. Sua execução movimenta os agentes no interior dos círculos sagrados. Também conhecido como "o Reis", em referência aos santos aos quais se atribui a criação das folias "no mundo", ele exige de seus executores e participantes o respeito a algumas regras

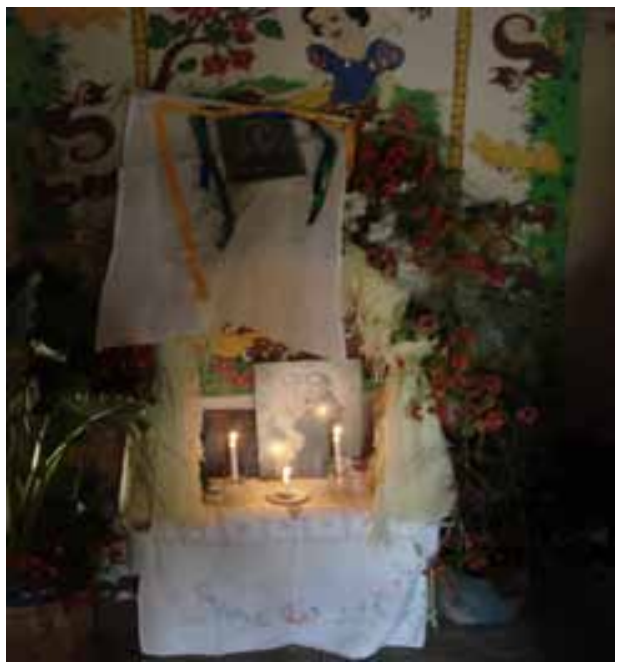
muito particulares ao longo de sua execução, possuindo clara e reconhecida eficácia religiosa. Durante a realização dos "cantorios", os foliões permanecem quase imóveis, enquanto os moradores e assistentes ficam em relativo silêncio. $O$ canto, neste momento, desempenha importante papel de mediação, possuindo evidentes características performativas, ao mesmo tempo instrumento de ação e de comunicação (PEREIRA, 2009) ${ }^{15}$.

Figura 4. O santuário de Santa Luzia Foto: Luzimar Paulo Pereira 
16 Marcel Mauss, em seu ensaio inacabado sobre a "prece", já havia alertado de que a oração é um rito particular dentro de todo um universo de outros atos definidos como ritos orais, tais como o juramento, o contrato verbal de aliança religiosa, a bênção, a maldição, $o$ voto, a dedicação oral, etc. As diferenças entre essas formas de ritos orais e a oração propriamente dita residiriam, segundo o autor, no fato de esta última ser entendida como "um meio de agir sobre os seres sagrados; estes é que são influenciados por ela, é nestes que ela suscita modificações" (MAUSS, 1999, p. 272). A oração se caracterizaria por seu caráter eminentemente propiciatório $e$ precatório, como pedidos feitos pelos homens aos deuses. Por essa razão, ela seria diferente da simples bênção, porque esta procura agir, ainda que sob a influência das divindades, diretamente sobre algo que se quer ver envolto e protegido por um poder considerado sagrado. Obviamente, segundo o próprio Mauss, há orações que podem ser também bênçãos, assim como há bênçãos que são verdadeiros encantamentos mágicos. Os limites que separam um e outro desses ritos orais são, muitas vezes, fluidos e de difícil definição.
Os "cantorios" instrumentalizam os contatos que seus realizadores pretendem estabelecer entre si e com seus santos padroeiros. Ainda que sejam tratados pelos devotos como uma espécie de prece, eles são frequentemente muito mais do que is$\mathrm{so}^{16}$. Durante as atividades rituais, os cantadores, além de conduzirem seus cantos propiciatórios aos santos de sua devoção, também: 1) narram passagens da vida das personagens sagradas aos quais eles são dedicados; 2) apresentam o grupo de foliões aos moradores e demais interlocutores; 3 ) introduzem pedidos de ingresso nas casas visitadas pelos ternos; 4) formulam os pedidos de donativos em seu nome, no dos imperadores $\mathrm{e}$ no das divindades; 5 ) realizam os agradecimentos e distribuem bênçãos dos santos aos moradores e seus familiares; 6) cantam as promessas feitas e confirmam a eficácia de seu cumprimento pelo fiel; 7) fazem adorações a altares; 8) dão significados a gestos e acontecimentos imprevistos que ocorrem durante a jornada ritual, etc. ${ }^{17}$ Os usos e significados comunicativos (e ativos) dos cantos cerimoniais parecem evidentes.

A diversidade funcional dos cantos indica a complexidade das trocas estabelecidas entre homens e divindades ${ }^{18}$. O "cantorio" da transmissão da bandeira, realizado na casa de dona Juraci, pode ser corretamente compreendido como exemplo bastante fiel da complexidade e da múltipla funcionalidade dos rituais. A rigor, ele pode ser apresentado através de um esquema performativo de caráter processual, em que uma "entrada" (sequências 1 e 2) é seguida de um período de maior "liminaridade" (sequências 3 e 4) para desembocar numa "saída" ou "desagregação" (sequências 5 e 6).

1- Os primeiros versos do "cantorio" (as duas primeiras quadras) evocam o Sinal da cruz, por meio do qual os foliões estabelecem a passagem para o mundo do cerimonial. A narrativa apresenta os significados desse breve rito manual, como um dom divino e ao mesmo tempo instrumento de proteção ("Pelo sinal da Santa Cruz (...)/ Que nos livrai dos inimigos / Com o sinal que Deus deixou"). Ela também descreve verbalmente o movimento que o "sinal da Santa Cruz" exige para ser realizado manualmente ("O nome do Pai, eu faço na testa / Do Filho, eu faço em meu peito / Do Espírito, eu faço nos ombros / Do esquerdo para o direito"). A fala ocupa o lugar do gesto para expressar os mesmos significados rituais. 
2- Num segundo momento, os cantadores iniciam o cabeçalho do "cantorio"19. As quadras são dedicadas a apresentar os personagens e chamar sua atenção para o que se estará fazendo ali. Em primeiro lugar, os versos indicam a unidade do grupo de foliões em oposição aos imperadores. Realizados na terceira pessoa do plural, eles possuem ao mesmo tempo a função referencial de "explicar" (segundo termo nativo) os sentidos do próprio ritual e conativa ao pedir a atenção do imperador e de sua esposa para o que vai ocorrer ("Vamos receber a folia / Desse nobre imperador"/ "Ô meu nobre imperador/ Com sua nobre rainha ( Vamos receber sua folia / [da] Senhora Santa Luzia") (JAKOBSON, 1975).

3- Num terceiro momento, o "cantorio" adentra, finalmente, o centro das atividades cerimoniais: começa, enfim, a transmissão da folia. Os versos, realizados na primeira pessoa do singular, ressaltam a autoridade do capitão e pedem a atenção dos imperadores para o que eles devem efetivamente fazer a seguir ("Ora, meu nobre imperador/ Escuta o que eu vou falar/A folia de Santa Luzia/Vós irá nos entregar (...) Faz a vênia com o retrato/ E entrega ao meu alferes"). A fala cerimonial é seguida pelo movimento do imperador, que caminha em direção aos foliões e entrega ao bandeireiro, que está de joelhos, o artefato. Precisamos notar, por um lado, que este trecho do "cantorio" exige a atenção de seu destinatário. Por outro, ele indica uma distinção entre aqueles que sabem o que se deve fazer (o alferes que caminha sem ser ordenado) e aqueles que precisam ser guiados para o que se deve fazer (os imperadores);

4- Num quarto momento, o ritual da transmissão precisa se completar. Não basta que a bandeira (a própria Santa Luzia encarnada, "nossa padroeira") seja efetivamente passada aos foliões. É necessário que os demais artefatos também sejam transmitidos. Os destinatários do ato comunicativo mudam. Agora o capitão se dirige a "seus foliões", pedindo que eles se ajoeIhem diante do santuário para receber a folia, representada pelas toalhas e pelos instrumentos musicais. Além disso, os versos estabelecem paralelos entre a folia que está sendo entregue e a promessa do imperador, reforçando o caráter devocional do empreendimento: ("Ajoelhai meus folião/ Vamos receber essa promessa / Para cumprir com devoção" $)^{20}$.
17 Carlos Rodrigues Brandão (1977) já havia atentado para essa multiplicidade de usos e sentidos do "cantorio".

18 As sequências de "cantorios" (ou mesmo um único canto em particular) parecem propor alterações constantes entre remetentes (geralmente, os foliões), receptores (que podem ser os próprios cantadores, os imperadores, os moradores, os convidados, as cozinheiras, os serventes, os santos, Deus, entre outros personagens), mensagens, contextos (dados pelo próprio enquadramento do ritual), contatos (as formas de comunicação do ritual, seus cantos, objetos e movimento de corpos) e códigos (que precisam ser compartilhados) (JAKOBSON, 1975).

19 "No cabeçalho", me dizia um folião, "a gente tem que fazer a explicação; dizer o que que está fazendo ali, né?". Ele é tido como obrigatório a todos os procedimentos de um cantorio. "Não pode cantar sem cabeçaIho, não. Nem que seja curtinho, para economizar o tempo, tem que fazer" (folião, caderno de campo, 1.2.2008).

20 É preciso indicar que a transmissão, nesse contexto, é mais simbólica do que efetiva. Durante o cantorio, os foliões já estão portando suas toalhas e carregando seus instrumentos. 


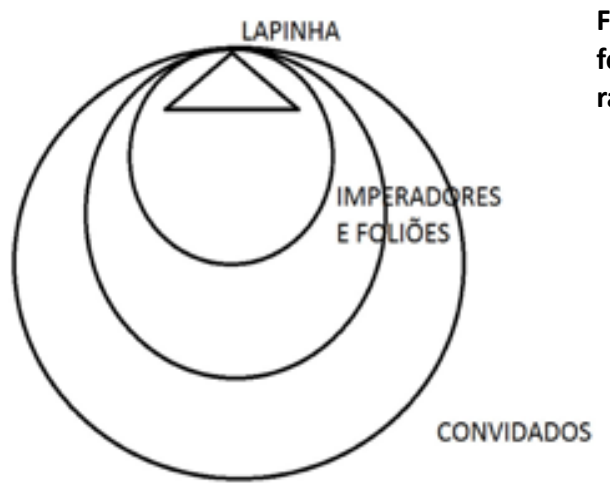

Figura 5. Diagrama de posições de foliões, imperadores e convidados durante os cantos da retirada

5- Os versos seguintes indicam o final da transmissão, quando os foliões dão início à despedida. Depois de anunciar que a folia já está entregue, o capitão pede, então, para que seus foliões se levantem (eles estavam de joelhos). Os procedimentos comunicativos do canto estabelecem uma metáfora entre esse gesto de se levantar e a própria ascensão de Santa Luzia aos céus ("Aqui nós ajoelhemo./ Como a santa subiu para o céu / Nós também se alevantemo). Em seguida, o cantador pede que os próprios imperadores e sua família se aproximem, se ponham de joelhos e se despeçam de sua folia (a folia é ao mesmo tempo a bandeira e a própria Santa Luzia) (“Ô, meu nobre imperador / Enconvida sua família / Para beijar o retrato santo / Despedir da sua folia").

6- Finalmente, os versos apontam para a saída dos foliões. O capitão informa o tempo, os rumos e os objetivos da jornada dos cantadores, reiterando, assim, algumas informações apresentadas no cabeçalho ("A santa vai retirar / Amanhã ao romper do dia / Nós havemo de aqui chegar/ E a santa vai retirando,/ Retratada na bandeira. Vamos cumprir sua promessa / Nesse mundo de meu Deus"). Os foliões proferem a quadra final (uma espécie de 'amém') e encerram seus cantos. Vivas e fogos de artifício finalizam o pequeno ritual.

O "cantorio" estabelece ritualmente a constituição de duas séries paralelas, entoadas no canto dos foliões e representadas na disposição dos artefatos e no posicionamento de seus principais personagens. A relação entre os termos de cada uma dessas séries nos é dada por procedimentos linguísticos (a metáfora e a metonímia nos cantos) combinados às operações manuais baseadas no contágio e na semelhança (TAMBIAH, 1985). As colunas são encabeçadas, de um lado, pelos imperadores, e, de outro, pelos foliões (ambos estão, do início ao fim do ritual, frente a frente). Na série articulada pelos organizadores e patrocinadores dos festejos, podemos incluir o santuário, a casa e o mundo feminino, que, em conjunto, indicam a "fixação" e a imobilidade, em oposição à série seguinte, marcada essencialmente pelo "movimento". No eixo formado pelos foliões, podemos observar o espaço vazio (em oposição ao altar), o mundo (de onde vêm os cantadores e para onde eles vão, após o ritual da retirada) e o universo masculino. 


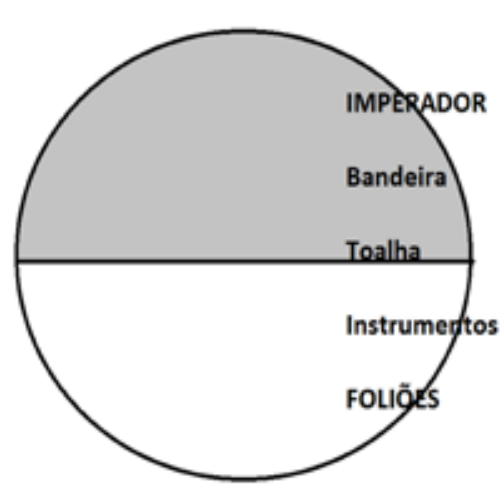

Figura 6. Diagrama da passagem dos artefatos religiosos

Entre as duas filas, encontramos a tríade de artefatos rituais: a bandeira, as toaIhas e os instrumentos musicais - os únicos elementos do cerimonial que atravessam os limitem instituídos entre os cantadores, de um lado, e os imperadores, de outro. Não se deve esquecer, também, que os artefatos são igualmente elementos de mediação com o cosmo, articulando alto e baixo, dentro e fora, passado, presente e futuro, etc., encarnando a noção de sagrado que estrutura os festejos (GONÇALVES, 2003; PEREIRA, 2004; 2009; BITTER, 2010) (Figura 6).

Os objetos que são transmitidos de uma série à outra podem, individualmente, ser associados, de modos distintos, aos dois eixos performativos. A bandeira é entregue pelo imperador, mas parece ser feita para os foliões, como a guia de sua jornada cerimonial. Além do mais, o retrato é ao mesmo tempo feminino e masculino (produzido e montado por mulheres, ele será sempre manuseado por homens, especialmente, pelo alferes) ${ }^{21}$. No limite, embora guardado na residência dos imperadores, seu destino inelutável é viajar, sair pelo mundo com os cantadores. Embora estejam igualmente associadas às duas séries, as toalhas também podem muito facilmente ser consideradas mais próximas dos foliões do que dos imperadores (muitos cantadores possuem suas próprias toalhas). Feitos por mulheres, os artefatos, contudo, nunca são usados por elas. Além disso, assim como os instrumentos musicais, as toalhas já estão com os cantadores durante o cantorio; o que parece indicar, desde o começo, maior proximidade com 21 A bandeira é produzida por algumas mulheres qualificadas para o serviço. Seu trabalho consiste em transportar para o tecido a representação iconográfica do santo de acordo com certos modelos (outras bandeiras ou quadros de santos) fornecidos pelos devotos. eles. As violas, os violões, as caixas, entre outros instrumentos musicais, parecem, assim, ter destino semelhante ao das toalhas, sem, no entanto, possuir valor religioso mais destacado. Eles compõem os artefatos "menos sagrados" de todos os objetos sagrados (PEREIRA, 2009). Um pequeno quadro de posições e correlações (Quadro 1) articula as duas séries que estou apresentando. 


\begin{tabular}{|c|c|c|c|}
\hline Série 1 & & & Série 2 \\
\hline Imperadores & & & Foliões \\
\hline Santuário & Bandeira & $\begin{array}{c}\text { Toalhas / } \\
\text { Instrumentos }\end{array}$ & Música \\
\hline Casa & & & Mundo \\
\hline Feminino & & & Masculino \\
\hline Fixidez & & & Mobilidade \\
\hline
\end{tabular}

Os procedimentos performativos são orientados no sentido de regular a passagem dos artefatos da primeira à segunda série de categorias. O movimento dos objetos é visualmente observado, tangivelmente experimentado e auditivamente percebido pelo "cantorio", entendido em todas as suas dimensões (poesia cantada, música ritual, movimento dos corpos e manipulação de objetos). O ritual encena um deslocamento de foco (que passa do altar para os cantadores) enquanto duas operações simultâneas são realizadas: uma agregação (a de imperadores e foliões) e uma separação (da bandeira e do santuário). De um lado, a retirada estabelece uma aliança entre os principais personagens do ritual. Incompletos no início das festividades, ambos agora são partes de uma mesma entidade: "a folia que vai viajar pelo mundo". A passagem é visualmente observada por clara inversão ritual, quando, em seguida ao gesto dos foliões de se colocarem de joelhos diante do organizador e patrocinador dos festejos, vemos os próprios imperadores se rebaixarem diante dos foliões.

De outro lado, os procedimentos performativos da retirada também nos indicam uma separação. Terminado o ritual, o altar é o trono vazio. A divindade está, pois, a caminhar. A fonte do poder religioso é deslocada do santuário (na casa) para os foliões (que irão andar "pelo mundo"). A partir de então, a jornada será constituída em torno de uma lógica paradoxal. Os cantadores devem, em primeiro lugar, seguir "para frente", num movimento de expansão que os leva ao encontro de outras casas e outros devotos. Ao mesmo tempo, porém, sua viagem está idealmente se projetando para o retorno ao santuário em que ela começou. A expansão e a concentração parecem ser claramente observadas na articulação entre a fixação (do altar, da casa) e a mobilidade (da bandeira e do mundo). A ideia contida na noção de giro torna-se, então, evidente. Trata-se de sair para voltar, cujo sentido mais geral é a futura reunificação entre o santuário e a bandeira.

\section{REFERÊNCIAS BIBLIOGRÁFICAS}

AUSTIN. J.L. Quando dizer é fazer. Porto Alegre: Artes Médicas, 1990.

BAUDRILLARD, Jean. O sistema de objetos. São Paulo: Perspectiva, 2004. 
BITTER, Daniel. A bandeira e a máscara: a circulação de objetos rituais nas folias de reis. Rio de Janeiro: 7Letras, 2010.

BRANDÃO, Carlos Rodrigues. A folia de reis de Mossâmedes. Rio de Janeiro: Funarte, 1977. Cadernos de Folclore Funarte, 20.

. Sacerdotes da viola. Petrópolis: Vozes, 1981.

CASCUDO, Luís da Câmara. Dicionário do folclore brasileiro. Rio de Janeiro: Ediouro, 1998.

CHAVES, Wagner. "Recebeis meu Bom Jesus com sua nobre folia": reflexões sobre a eficácia do canto nas folias norte-mineiras do alto-médio São Francisco. Textos escolhidos de cultura e arte populares, Rio de Janeiro, v.3, n.1, 2006.

DOUGLAS, Mary. Pureza e perigo. Lisboa: Edições, 70, 1991.

GONÇALVES, José Reginaldo Santos. "O patrimônio como categoria de pensamento". In ABREU, Regina; CHAGAS, Mário (org.). Memória e patrimônio. Rio de Janeiro: DP\&A, 2003.

HUBERT. Henri. \& MAUSS, Marcel. Ensaio sobre a natureza e a função do sacrifício. In MAUSS, M. Ensaios de Sociologia. São Paulo: Perspectiva, 1999.

JAKOBSON, Roman. Linguística e comunicação. São Paulo: Cultrix, 1975.

LEACH, Edmund. Antropologia. São Paulo: Ática, 1983.

. Once a knight is quite enouch: como nasce um cavaleiro britânico. In Mana. vol. 6. n.1 : Rio de Janeiro, Apr. 2000, pp. 31-56.

MALINOWSKI, Bronislaw Kasper. "O problema do significado em linguagens primitivas". In OGDEN, C. K. \& RICHARDS, I.A (orgs.). O significado de significado: um estudo da influência da linguagem sobre o pensamento e sobre a ciência do simbolismo. Rio de Janeiro: Jorge Zahar Editores, 1976.

MAUSS, Marcel. A Prece. In MAUSS, M. Ensaios de sociologia. São Paulo: Perspectiva, 1999.

Sociologia e antropologia. São Paulo: Cosac \& Naify, 2003.

PEREIRA, Luzimar Paulo. Os andarilhos dos Santos Reis: um estudo etnográfico sobre folia de reis, bairro rural e sistemas de prestações totais. Dissertação, mestrado em Desenvolvimento, Agricultura e Sociedade no CPDA/UFRRJ, 2004.

. Os giros do sagrado: um estudo etnográfico sobre folias em Urucuia-MG. Rio de Janeiro: Tese de doutoramento em antropologia cultural, PPGSA/UFRJ, 2009.

QUEIROZ, Maria Isaura Pereira. O campesinato brasileiro. Petrópolis/São Paulo: Vozes/ Edusp, 1973.

REILY, Suzel Ana. The Songs of the Magi: Enchanted Journeys in Southeast Brazil. Chicago: University of Chicago Press, 2002.

TAMBIAH, Stanley Jeyaraja. Culture, Thought and Social Action. Cambridge: Harvard University Press, 1985.

TURNER, Victor. O processo ritual. Petrópolis: Vozes, 1974.

. La selva de los símbolos: aspectos del ritual ndembu. México/Madrid: D.F./Siglo Ventuno Editores, 1980.

VAN GENNEP, Arnold. Os ritos de passagem. Petrópolis: Vozes, 1978.

Luzimar Paulo Pereira é doutor em ciências humanas (antropologia cultural) pelo Programa de Pós-Graduação em Sociologia e Antropologia, da Universidade Federal do Rio de Janeiro. Atualmente é professor e pesquisador do Departamento de Antropologia Cultural e do Programa de Pós-Graduação em Sociologia e Antropologia do IFCS/UFRJ. 